\title{
Serum uric acid is associated with disease severity and may predict clinical outcome in patients of pulmonary arterial hypertension secondary to connective tissue disease in Chinese: a single-center retrospective study
}

Jingya Wang ${ }^{1,2}$, Yuanyuan Wang ${ }^{1}$, Xiaodi Li ${ }^{1}$, Yingheng Huang ${ }^{1}$, Xiaoxuan Sun ${ }^{1}$, Qiang Wang ${ }^{1 *}$ and Miaojia Zhang ${ }^{1 *}$ (D)

\begin{abstract}
Background: Previous studies have shown that serum uric acid (UA) levels are correlated with the severity of idiopathic pulmonary arterial hypertension (IPAH) and are predictors of disease prognosis. Still, few studies have explored the value of serum UA in pulmonary arterial hypertension secondary to connective tissue disease (CTD$P A H)$. This retrospective study aimed to investigate the clinical value of serum UA levels in patients with CTD-PAH.

Methods: Fifty CTD-PAH patients were enrolled in our study, from which baseline UA levels, respective variations, and additional clinical data were collected. The potential association between baseline UA level and severity of CTD-PAH was investigated. Furthermore, the relationship between baseline UA and survival rate of CTD-PAH patients, as well as between UA variations and survival rate of pulmonary hypertension secondary to connective tissue disease (CTD-PH) patients was discussed.
\end{abstract}

Results: Baseline serum UA levels were positively correlated with pulmonary vascular resistance (PVR). During the follow-up period, 3 CTD-PAH and 12 CTD-PH patients died. Kaplan-Meier survival curves showed lower survival rate in patients with hyperuricemia than in patients with normouricemia, in both groups (CTD-PAH group $p=0.041$, CTD-PH group $p=0.013$ ). Concerning serum UA variations, patients with persistent hyperuricemia showed the lowest survival rate when compared with patients with steady normouricemia $(p=0.01)$ or patients with decresing serum UA levels, i.e. undergoing from a status of hyperuricemia to a status of normouricemia $(p=0.023)$.

Conclusion: Baseline serum UA levels might predict severity of CTD-PAH. Together with baseline values, changes of uric acid level may predict the clinical prognosis of the disease.

Keywords: CTD-PAH, Serum uric acid, Severity, Prognosis

\footnotetext{
* Correspondence: jerrytortoise@163.com; mizhang@njmu.edu.cn

'Department of Rheumatology, The First Affiliated Hospital of Nanjing Medical University, Nanjing, China

Full list of author information is available at the end of the article
}

(c) The Author(s). 2020 Open Access This article is licensed under a Creative Commons Attribution 4.0 International License, which permits use, sharing, adaptation, distribution and reproduction in any medium or format, as long as you give appropriate credit to the original author(s) and the source, provide a link to the Creative Commons licence, and indicate if changes were made. The images or other third party material in this article are included in the article's Creative Commons licence, unless indicated otherwise in a credit line to the material. If material is not included in the article's Creative Commons licence and your intended use is not permitted by statutory regulation or exceeds the permitted use, you will need to obtain permission directly from the copyright holder. To view a copy of this licence, visit http://creativecommons.org/licenses/by/4.0/. The Creative Commons Public Domain Dedication waiver (http://creativecommons.org/publicdomain/zero/1.0/) applies to the data made available in this article, unless otherwise stated in a credit line to the data. 


\section{Introduction}

Pulmonary arterial hypertension (PAH) is a lifethreatening and refractory disease, associated with progressive pulmonary vascular remodeling and increased pulmonary vascular resistance, ultimately leading to right ventricular failure and death. Connective tissue disease (CTD) is the primary cause of PAH [1]. In turn, $\mathrm{PAH}$ is the third cause of death among CTD patients, highlighting the impoatance of a proper evaluation of disease severity and prognosis. Serum uric acid (UA), the end product of purine metabolism, has been purposed as a prognostic marker of pulmonary arterial pressure [2-4], which is related with PAH aggressiveness, [5-13], and has been reported to predict the clinical outcome of the disease $[6,8,13-19]$. However, serum UA can be generated in varying contexts, such as cardiac overproduction, renal impairment, diet, or use of diuretics in right-sided heart failure. Therefore, the use of $\mathrm{UA}$ as an indicator of PAH severity and prognosis remains controversial. The association between UA and CTD-PAH has been previously described, and up to date, the evidence suggests that: 1) UA levels above $357 \mu \mathrm{mol} / \mathrm{L}$ are associated with $\mathrm{PAH}$ in systemic lupus erythematosus (SLE) [20]; 2) Serum UA levels are correlated with disease severity in PAH secondary to systematic sclerosis (SSc-PAH) [21]; 3) Serum baseline UA levels may predict clinical outcome in patients with CTD-PH [18]. In this context, the authors concluded that UA levels were correlated to pro-BNP and SPAP. In contrast, the relationship between serum UA levels and hemodynamic parameters in CTD-PAH patients was rarely discussed. Moreover, the numerical criteria for defining pulmonary hypertension $(\mathrm{PH})$ are inconsistent with each other. Finally, it is still to uncover the association of UA concentration variations and the prognosis of CTD-PH patients. Therefore, we performed a retrospective study, to disclose the correlation between baseline UA levels and CTD-PAH severity and prognosis. We further studied the clinical relevance of UA variations to the outcome of CTD-PH patients.

\section{Methods}

\section{Design}

CTD-PAH patients were evaluated and treated in the rheumatology department in the first affiliated hospital of Nanjing Medical University during the period of 2009-2018. This study was approved by the Medical Ethics Committee of the First Affiliated Hospital of Nanjing Medical University (number 2018-SR-333).

\section{Patients}

In this study, 197 patients were screened, and according to the inclusion/exclusion criteria, and 50 patients were enrolled. The screening process was as follows (Fig. 1).

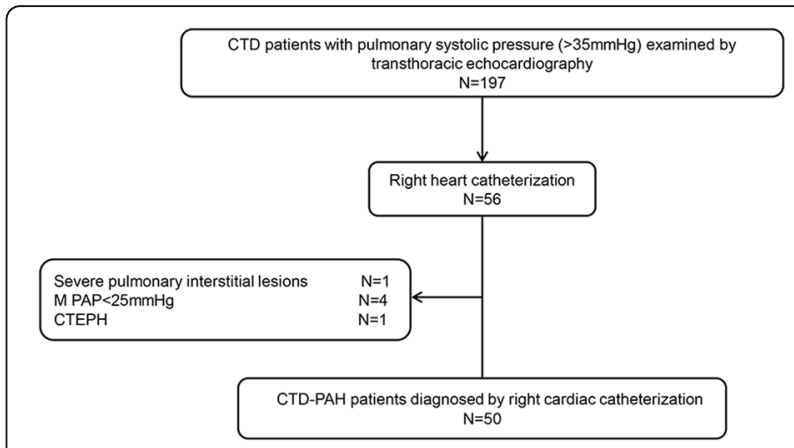

Fig. 1 Inclusion flow chart of CTD-PAH patients diagnosed by RHC

Inclusion criteria: a. compliance with the diagnostic criteria for connective tissue diseases. CTD were diagnosed as follows: SLE was diagnosed according to 1997 American Rheumatism Association (ACR) criteria, primary Sjogren's syndrome (pSS) was defined according to 2002 international classification criteria, systematic sclerosis (SSc) was defined according to 1980 ACR criteria, mixed connective tissue disease (MCTD) was defined by Sharp criteria. b. diagnosis of pulmonary hypertension by Right-heart catheterization (RHC): mean pulmonary arterial pressure $(\mathrm{m} P A P) \geq 25 \mathrm{mmHg}$ at rest, pulmonary arterial wedge pressure (PAWP) $\leq 15 \mathrm{mmHg}$ and pulmonary vascular resistance $(\mathrm{PVR}) \geq 3$ Wood Units. Exclusion criteria: a. patients with significant interstitial lung disease (ILD) or chronic obstructive pulmonary disease based on the results of chest high-resolution computed tomography (HRCT), b. evidence of pulmonary venous hypertension (pulmonary capillary wedge pressure $>15 \mathrm{mmHg}$ ), c. chronic thromboembolic disease, based on the results of computed tomography angiography, d. patients with a history of IPAH, drug or toxin exposure, human immunodeficiency virus (HIV) infection, portal hypertension or any other diseases known to be associated with pulmonary hypertension $(\mathrm{PH})$, e.

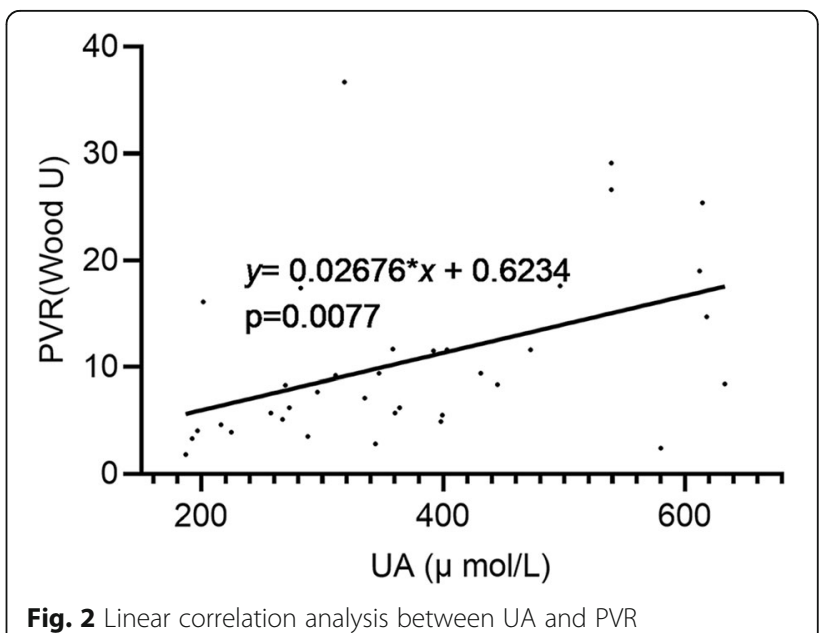


Table 1 Baseline Characteristic of normouricemia and hyperuricemia groups

\begin{tabular}{|c|c|c|c|}
\hline & Hyperuricemia group $(n=23)$ & Normouricemia group $(n=27)$ & $p$ \\
\hline Gender (women/ men) & $21 / 2$ & $26 / 1$ & \\
\hline Age, $Y$ & $40.17 \pm 3.11$ & $38.22 \pm 2.36$ & \\
\hline SLE & $7(14 \%)$ & $13(26 \%)$ & \\
\hline SS & $8(16 \%)$ & $6(12 \%)$ & \\
\hline CTD & $4(8 \%)$ & 0 & \\
\hline SSC & $3(6 \%)$ & $2(4 \%)$ & \\
\hline SLE/SS & $1(2 \%)$ & $1(2 \%)$ & \\
\hline MCTD & 0 & $5(10 \%)$ & \\
\hline Body Mass Index, kg/m^2 & $22.0 \pm 0.1$ & $22.28 \pm 0.71$ & ns \\
\hline WHO functional class, III-IV/I-II & $15 / 8$ & $17 / 10$ & ns \\
\hline 6MWD, m & $390.8 \pm 30.85$ & $404.1 \pm 27.93$ & ns \\
\hline UA, $\mu \mathrm{mol} / \mathrm{L}$ & $467.0 \pm 19.67$ & $277.7 \pm 10.02$ & ns \\
\hline Creatinine, $\mu \mathrm{mol} / \mathrm{L}$ & $63.24 \pm 3.02$ & $63.14 \pm 5.33$ & ns \\
\hline NT-pro BNP, pg/ml & $2368 \pm 662.80$ & $1270 \pm 465.80$ & ns \\
\hline Treatment with diuretics, yes/no & $5 / 18$ & $6 / 21$ & ns \\
\hline \multicolumn{4}{|l|}{ echocardiography } \\
\hline PASP, $\mathrm{mmHg}$ & $83.13 \pm 4.93$ & $74.19 \pm 3.40$ & ns \\
\hline TAPSE, cm & $1.53 \pm 0.11$ & $2.15 \pm 0.36$ & ns \\
\hline \multicolumn{4}{|l|}{ right heart catheterization } \\
\hline Rap, mmHg & $8.13 \pm 1.22$ & $6.00 \pm 0.91$ & ns \\
\hline mPAP, mmHg & $45.43 \pm 2.41$ & $45.70 \pm 2.09$ & ns \\
\hline PAWP, mmHg & $8.91 \pm 0.76$ & $8.58 \pm 0.77$ & ns \\
\hline $\mathrm{CO}, \mathrm{L} / \mathrm{min}$ & $3.75 \pm 0.37$ & $5.19 \pm 0.51$ & 0.029 \\
\hline $\mathrm{Cl}, \mathrm{L} / \mathrm{min} / \mathrm{m}^{2}$ & $2.31 \pm 0.24$ & $3.15 \pm 0.28$ & 0.028 \\
\hline PVR, Wood U & $12.77 \pm 1.85$ & $8.50 \pm 1.93$ & 0.0244 \\
\hline SVO2, \% & $57.81 \pm 2.51$ & $65.13 \pm 1.97$ & 0.029 \\
\hline
\end{tabular}

Numerical values were expressed as mean \pm standard error. Comparisons between two groups were calculated by Student's unpaired $t$ test or Fisher's exact test SLE systemic lupus erythematosus, SS Sjogren's syndrome, CTD connective tissue disease, SSc systematic sclerosis, SLE/SS systemic lupus erythematosus /Sjogren's syndrome, MCTD mixed CTD (MCTD) was defined by Sharp criteria, WHO functional class World Health Organization Cardiac Function Classification, 6MWD 6-min walking distance, NT-pro BNP N-terminal pro-B-type natriuretic peptide, PASP pulmonary artery systolic pressure, TAPSE systolic displacement of tricuspid annulus, $R A P$ right atrial pressure, $m P A P$ mean pulmonary arterial pressure, $P A W P$ pulmonary artery wedge pressure, $C O$ cardiac output, $C I$ cardiac index, $P V R$ pulmonary vascular resistance, SVO2 mixed venous oxygen saturation

patients with gout, f. patients with renal insufficiency, g. systemic vasculitis was excluded.

Hyperuricemia was defined as serum UA levels of women $\geq 357 \mu \mathrm{mol} / \mathrm{L}$ and men $\geq 420 \mu \mathrm{mol} / \mathrm{L}$.

\section{Data collection and outcome assessment}

We used a uniform evaluation chart to collect patient information, which included demographic data, clinical manifestations, laboratory results, and treatment regimens. Demographic data included gender, age, height, weight, PAH symptoms at the diagnosis of CTD-PAH with right cardiac catheter. Recruitment date was defined as the RHC date for CTD-PAH patients. As for treatment regimens, steroid and immuno-suppressors were documented for the dosage and administration route. Use of diuretics and PAH-targeted medicine were also recorded and analyzed. Blood samples for baseline measurements were obtined from a peripheral vein within 1 week of the first diagnostic catheterization from hemodynamically stable patients not receiving specific PAH drugs. UA, creatinine, fasting glucose, N-terminal pro-B-type natriuretic peptide (NT-pro BNP) and autoantibodies were measured in the central laboratory of the first affiliated hospital of Nanjing Medical University. Transthoracic echocardiography was examined in all suspicious PAH patients. RHC was performed in 50 patients during hospitalization. The baseline hemodynamic parameters were measured in all patients.

To study disease progression, we performed outpatient follow-up and telephone follow-up. The first was performed every 3-6 months, to collect the clinical symptoms, the results of cardiac ultrasound and the levels of 
Table 2 Analysis of variables associated with serum uric acid levels in patients of CTD-PAH

\begin{tabular}{|c|c|c|c|c|}
\hline & $\mathrm{R}$ squared & Pearson $r$ & 95\% confidence interval & $P$ value \\
\hline Age & 0.004175 & & -2.017 to 3.174 & 0.6557 \\
\hline BMl & 0.00257 & & -0.3424 to 0.2499 & 0.7438 \\
\hline FBS & 0.001525 & & -0.2842 to 0.3543 & 0.8159 \\
\hline creatinine & 0.3106 & & 0.2891 to 0.7444 & 0.0003 \\
\hline WHO functional class, I/II/III/IV & 0.04782 & & -0.06354 to 0.4685 & 0.1271 \\
\hline 6MWD & 0.09445 & & -1.204 to 0.3133 & 0.2302 \\
\hline NT-pro BNP & 0.1291 & 0.3593 & 0.05378 to 0.6034 & 0.0228 \\
\hline PASP & 0.08235 & 0.287 & 0.05005 to 3.258 & 0.0433 \\
\hline Rap & 0.09764 & 0.3125 & 0.02772 to 0.5503 & 0.0325 \\
\hline PAWP & 0.0272 & & -0.1318 to 0.4345 & 0.2734 \\
\hline $\mathrm{CO}$ & 0.1418 & -0.3766 & -0.6035 to -0.09333 & 0.0108 \\
\hline $\mathrm{Cl}$ & 0.1549 & -0.3936 & -0.6160 to -0.1130 & 0.0075 \\
\hline PVR & 0.1908 & 0.4369 & 0.1264 to 0.6694 & 0.0077 \\
\hline SVO2\% & 0.1073 & & -0.6069 to 0.02402 & 0.0673 \\
\hline
\end{tabular}

Pearson correlation analysis was used to evaluate the correlation between the indicators

$B M I$ body mass index, FBS fasting blood sugar

uric acid of the patients. Telephone follow-up was used to monitor clinical outcome. The primary endpoint was all-cause mortality. The survival rate of CTD-PAH patients was estimated from the date of first catheterization until 2 years, or the date of death.

\section{Statistical analysis}

Numerical values were expressed as mean \pm standard error. Comparisons between two groups were calculated by Student's unpaired $t$ test or Fisher's exact test. Pearson correlation analysis was used to evaluate the correlation between the indicators. Univariate correlation analysis and linear regression were used to analyze the related factors of elevated UA level. Survival curves were derived using the Kaplan-Meier method and were compared using log-rank test. $P$ value $<0.05$ was considered statistically significant. Statistical analyses were performed using SPSS.V20 or GraphPad Prism 8.0, Fig. 2 was made with GraphPad Prism 8.0, and all the survival curves were drawn in the Sanger box.

\section{Results}

Fifty patients with CTD-PAH (47 women, average age $38.5 \pm 0.3$ years, 3 men, average age $49.3 \pm 13.7$ years) were included in this study.

Table 3 Linear regression analysis of variables associated with PVR in patients of CTD-PAH, the independent variable is UA

\begin{tabular}{llllll}
\hline $\begin{array}{l}\text { Independent } \\
\text { variable }\end{array}$ & \multicolumn{2}{l}{ Non-standardization coefficient } & t & Sig. \\
\cline { 2 - 3 } & $\mathbf{B}$ & Standard error & & \\
\hline UA & 0.027 & 0.01 & 2.793 & 0.009 \\
\hline
\end{tabular}

Baseline characteristics of the normouricemia and the hyperuricemia groups (Table 1)

The 50 patients were separated into two groups based on serum UA levels: normouricemia group (UA: women < $357 \mu \mathrm{mol} / \mathrm{L}$, men $<420 \mu \mathrm{mol} / \mathrm{L}$ ) and hyperuricemia group (UA: women $\geq 357 \mu \mathrm{mol} / \mathrm{L}$, men $\geq 420 \mu \mathrm{mol} / \mathrm{L}$ ). Compared with normouricemia group, superior vena cava pressure and PVR levels were significantly higher in the hyperuricemia group. Cardiac output $(\mathrm{CO})$, cardiac index $(\mathrm{CI})$ and mixed venous oxygen saturation $\left(\mathrm{SVO}_{2}\right)$ were significantly smaller in the hyperuricemia group. However, there were no significant differences between the two groups regarding demographic characteristics, clinical symptoms, World Health Organization Cardiac Function Classification (WHO-FC), parameters of ECHO, diuretics.

\section{Baseline serum UA levels and severity in CTD-PAH}

In univariate correlation analysis of variables associated with serum UA levels in CTD-PAH, baseline UA levels were positively correlated with pulmonary artery systolic pressure (PASP), right atrial pressure (RAP), PVR, creatinine and NTpro BNP, and negatively with $\mathrm{CI}$ and $\mathrm{CO}$ (Table 2). In linear regression, PVR correlated to baseline serum UA levels (adjusted $R^{2}=0.163$, (Table 3 ). Linear correlation analysis showed that PVR increased by 0.02676 Wood U with the increase of $1 \mu \mathrm{mol} / \mathrm{L}$ of UA levels (Fig. 2).

\section{Baseline uric acid levels and prognosis in patients with CTD-PAH}

During the follow up period ( 2 years) 3 patients died and 2 patients were lost to follow-up. There were no patients receiving lung or heart-lung transplant. The overall follow-up rate was $96 \%$. Kaplan-Meier survival curves, in 


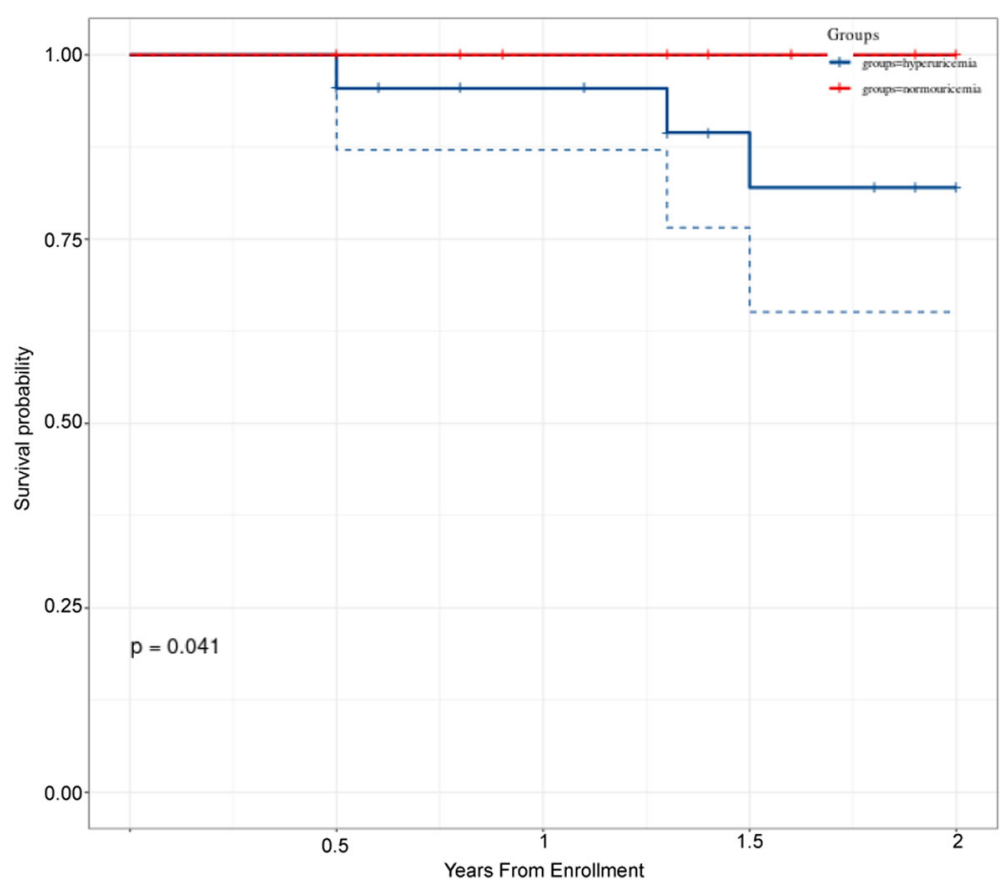

Fig. 3 Kaplan-Meier survival curves of normouricemia and hyperuricemia groups in CTD-PAH patients $(p=0.041)$

accordance with the two groups of the baseline serum UA levels, revela that hyperuricemic patients have lower survival rate than normouricemic patients ( $p=0.041$, Fig. 3).

\section{Variation of UA level and prognosis of patients with CTD-} $\mathrm{PH}$

We studied the relationship between UA level variations and the prognosis of patients with CTD-PH. Given the small the number of CTD-PAH patients with UA variations, we enrolled CTD-PH diagnosed using ultrasound. Fifty-seven patients with CTD-PH diagnosed by ECHO were enrolled in this part (Fig. 4).

We first whether ther is some association between baseline UA and the prognosis of CTD-PH patients. The

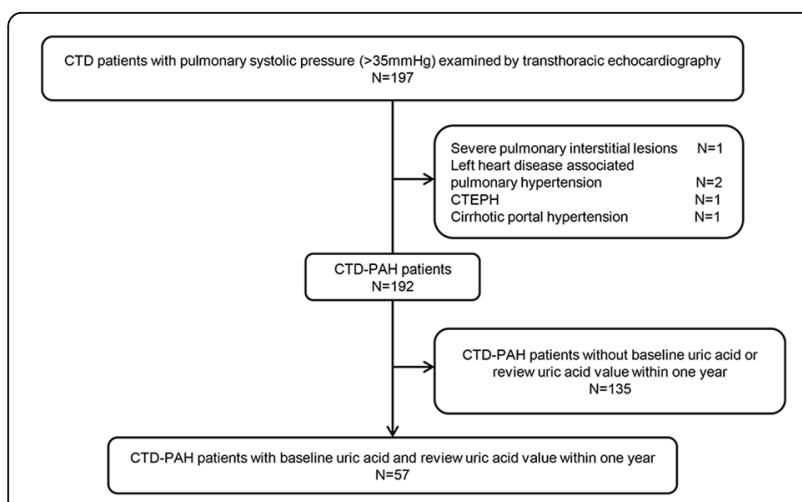

Fig. 4 Inclusion flow chart of CTD-PH patients with variation of UA
57 patients were separated into two groups based on baseline serum UA levels: normouricemia group (UA: women $<357 \mu \mathrm{mol} / \mathrm{L}$, men $<420 \mu \mathrm{mol} / \mathrm{L}$ ) and hyperuricemia group (UA: women $\geq 357 \mu \mathrm{mol} / \mathrm{L}$, men $\geq 420 \mu \mathrm{mol} /$ L). During the follow up period ( 2 years) 12 patients died and 2 patients were lost to follow-up. There were no patients receiving a lung or heart-lung transplant. The overall follow-up rate was $96.49 \%$. Kaplan-Meier survival curves, in accordance with the two groups of the baseline serum UA levels, revealed that hyperuricemic patients has lower survival rates than normouricemic patients ( $p=0.013$, Fig. 5a).

We further studied the relationship between UA level variation and the clinical outcome of CTD-PH patients, by performing a UA reexamination from 6 months to 1 year after the diagnosis of $\mathrm{PH}$ by echocardiography. Patients were then divided into 4 groups, according to UA levels at baseline and respective variations as follows: steady normouricemia (normouricemia $\rightarrow$ normouricemia; UA: $\mathrm{N} \rightarrow$ $\mathrm{N}$ ), increasing uricemia (normouricemia $\rightarrow$ hyperuricemia; UA: $\mathrm{N} \rightarrow \mathrm{H}$ ), steady hyperuricemia (hyperuricemia $\rightarrow$ hyperuricemia; $\mathrm{UA}: \mathrm{H} \rightarrow \mathrm{H}$ ) and decreasing uricemia (hyperuricemia $\rightarrow$ normouricemia; UA: $\mathrm{H} \rightarrow \mathrm{N}$ ), respectively. Details on UA variations and the follow up of participants are described in the Table 4. The survival rates among the four groups showed significant differences (Supplementary Figure $1 \mathrm{~A}, p=0.022$ ). Overall, steady heperuricemic patients showed the lowest survival rate, when compared to patients with steady normouricemia $(p=0.01)$ and patients with decreasing uricemia (UA: $\mathrm{H} \rightarrow \mathrm{N} ; p=0.023$; Fig. $5 \mathrm{~b}$ ). 

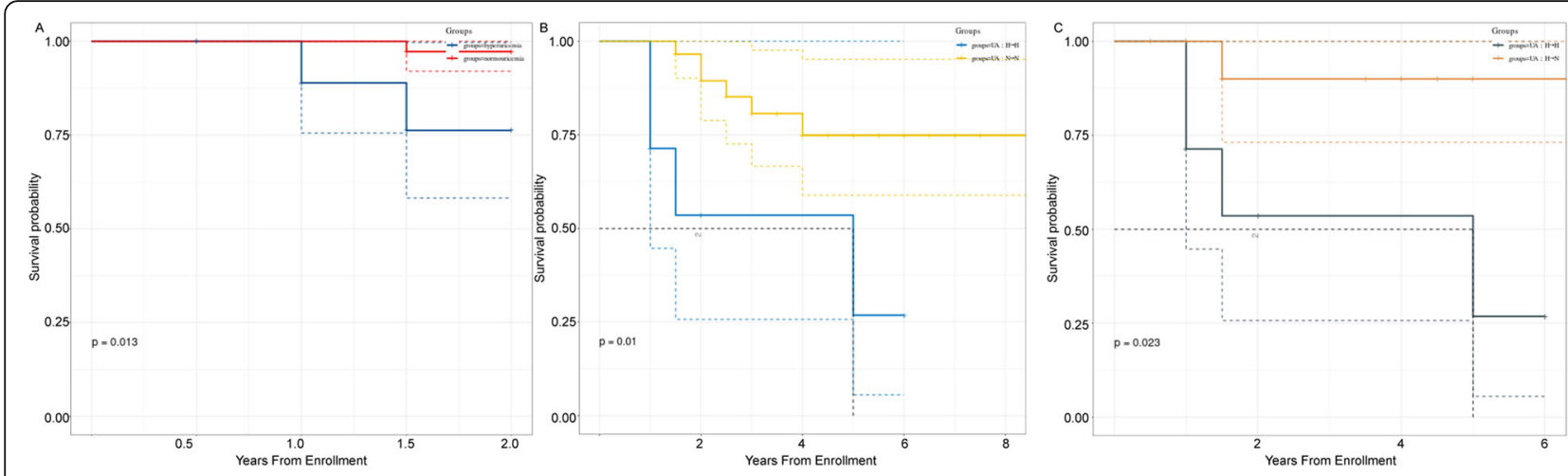

Fig. 5 a Kaplan-Meier survival curves for normouricemia and hyperuricemia groups according to the respective baseline UA levels in CTD-PH patients $(p=0.013)$; $\mathbf{b}$ Kaplan-Meier survival curves of patients with steady hyperuricemia $(U A: H \rightarrow H)$ and patients with steady normouricemia $(U A: N \rightarrow N) ; p=0.01$; c Kaplan-Meier survival curves of patients with steady hyperuricemia $(U A: H \rightarrow H)$ and patients with decreasing uricemia during the follow-up period $(\mathrm{UA}: \mathrm{H} \rightarrow \mathrm{N}), p=0.023$

In contrast there were no significant differences between the survival rate of UA: $\mathrm{N} \rightarrow \mathrm{N}$ and the UA: $\mathrm{N} \rightarrow \mathrm{H}$ groups (Supplementary Figure 1B; $p=0.83$ ).

\section{Discussion}

In the present study, we demonstrated that (1) hyperuricemia was detected in $46 \%$ of CTD-PAH patients, (2) baseline serum UA levels are positively correlated with pulmonary vascular resistance, (3) baseline UA levels might have a prognostic value in the context of CTDPAH and CTD-PH, at least for a period of 2 years, (4) UA level variations within 1 year might predict the longterm clinical outcome of CTD-PH patients.

Our retrospective study showed that baseline serum UA levels were positively correlated with pulmonary vascular resistance, and that pulmonary vascular resistance increased by 0.02676 Wood $U$ with the increase of $1 \mu \mathrm{mol} / \mathrm{L}$ of UA levels. Pulmonary vascular resistance measured with right cardiac catheterization is a critical parameter to account for during the assessment of PAH severity [22, 23]. Endothelial dysfunction of the pulmonary artery and proliferation of pulmonary artery smooth muscle cells are important promoters of pulmonary vascular resistance. On the one hand, uric acid may cause endothelial cell dysfunction, as its biosynthetic pathway generates reactive oxygen species (ROS) as a byproduct.
In hyperuricemia, the excessive production of $\mathrm{UA}$ is accompanied by excessive generates reactive oxygen species production, thus as UA is absorbed by endothelial cells, oxidative damage is increased. The presence of generates reactive oxygen species in the lungs might induce deterioration of endothelial function, reduced nitric oxide (NO) bioavailability [24] and increased pulmonary vascular resistance. On the other hand, in hyperuricemia conditions, UA enters vascular smooth muscle cells through an anion transporter [25] and stimulates proliferation by activating mitogen activated protein kinases (MAPK) [26], cyclooxygenase-2 (COX-2) [27], the vascular renin-angiotensin system [28] and the plateletderived growth factor (PDGF) and PDGF receptors [29]. An interesting question is whether UA may lead to proliferation of pulmonary artery smooth muscle cells and pulmonary vascular remodeling. In conclusion, UA may increase oxidative stress, weaken endothelial cell function and promote smooth muscle cell proliferation. Moreover, we purpose that serum UA may be used to assess the severity of CTD-PAH as well as IPAH.

In our study we observed that, compared with normouricemia group, the disease severity in conditions of hyperuricemia was increased, after 2 years of follow-up. We also observed that patients with baseline hyperuricemia had lower survival rate than those with baseline

Table 4 Details on UA variations in CTD-PH patients

\begin{tabular}{|c|c|c|c|c|c|}
\hline Group & $\begin{array}{l}\text { UA at baseline } \\
(\text { mean } \pm S D)(\mu \mathrm{mol} / \mathrm{L})\end{array}$ & $\begin{array}{l}\text { UA at reexamination } \\
(\text { mean } \pm S D)(\mu \mathrm{mol} / \mathrm{L})\end{array}$ & $\begin{array}{l}\text { number at } \\
\text { enrollment }\end{array}$ & censor & death \\
\hline UA: $\mathrm{H} \rightarrow \mathrm{H}$ & $509.6625 \pm 124.631$ & $519.025 \pm 133.6553$ & 8 & 1 & 4 \\
\hline UA: $\mathrm{H} \rightarrow \mathrm{N}$ & $477.9083 \pm 140.6724$ & $300.7083 \pm 46.3318$ & 12 & 0 & 1 \\
\hline UA: $N \rightarrow N$ & $260.27 \pm 54.92758$ & $256.7433 \pm 71.03973$ & 30 & 1 & 6 \\
\hline UA: $\mathrm{N} \rightarrow \mathrm{H}$ & $288.4571 \pm 44.99062$ & $412.3571 \pm 58.32638$ & 7 & 0 & 1 \\
\hline
\end{tabular}

$\mathrm{UA}: \mathrm{H} \rightarrow \mathrm{H}=$ steady hyperuricemia (hyperuricemia $\rightarrow$ hyperuricemia;), $\mathrm{UA}: \mathrm{H} \rightarrow \mathrm{N}=$ decreasing uricemia (hyperuricemia $\rightarrow$ normouricemia;), UA: $\mathrm{N} \rightarrow \mathrm{N}=$ steady normouricemia (normouricemia $\rightarrow$ normouricemia;), UA: $\mathrm{N} \rightarrow \mathrm{H}=$ increasing uricemia (normouricemia $\rightarrow$ hyperuricemia;) 
normouricemia, suggesting that baseline UA levels might predict the clinical outcome of CTD-PAH and CTD-PH patients. Our findings are consistent with previous studies showing the prognostic use of serum UA in IPAH. The levels of accurate biomarkers should fluctuate according to the course of the disease. The levels of serum UA are reported to decrease after PAH improvement [30]. Previous studies have also suggested that changes in serum uric acid levels might influence the outcome of pediatric PAH [31]. In this study, we observed that UA variation levels influenced the course of the disease, with steady hyperuricemic patients showing an overall lower survival rate that patients with steady normouricemia or patients with decreasing UA levels during the follow-up period. We also observed that the UA variations within 1 year may predict long-term survival rate of CTD-PH patients more accurately than baseline UA levels. Although we did not find significant differences in the survival rates between patients with steady normouricemia $(\mathrm{UA}: \mathrm{N} \rightarrow \mathrm{N}$ ) and patients with increasing uricemia (UA: $\mathrm{N} \rightarrow \mathrm{H}$ ). During the follow-up period, our results show that after 5 years, the survival rate of the later patientsis significantly lower than the first $(p=0.025$, Supplementary Figure $1 C$ and D). We hypothesize that our results would be enforced by including a higher number of patients in the analysis.

The results concerning the UA variations within 1 year and the survival rate of CTD-PH, displayed in Supplementary Figure 1A, show that steady normouricemic patients have lower overall survival than patients in $\mathrm{H} \rightarrow \mathrm{N}$ group, which is inconsistent with the results obtained so far. We hypothesize that such discrepancies might result from the fact that we have all-cause mortality as the endpoint, rather than $\mathrm{PH}$ specific mortality in our study. So there are other factors, such as co-infection, may also affect the survival rate of patients. Because this was a retrospective study, clinical deterioration events could not be accurately tracked, so we chose all-cause death. In future research, we will set the endpoint events as $\mathrm{PAH}$ or $\mathrm{PH}$ clinical deterioration events. Maybe, the result will be different. Indeed, this is a flaw in our research.

A previous study conducted by Simpson, and colleagues demonstrated an association between uric acid levels and disease risk, severity, and survival in systemic sclerosis-related pulmonary arterial hypertension. However, the major underlying Connective tissue diseases associated with PAH in Chinese patients appear to be systemic lupus erythematosus, systematic sclerosis, and primary Sjogren's syndrome [32]. Accordingly, in this study systemic lupus erythematosus, systematic sclerosis, primary Sjogren's syndrome, mixed connective tissue disease, and Connective tissue diseases are included.

Hyperuricemia might result from insulin resistance, renal dysfunction, gout, diuretic use and obesity, none of which is directly related to PAH. In this context, the value of uric acid in patients may be reduced, therefore we excluded gout and renal insufficiency at the time of inclusion. Moreover, we did not find significant differences in the level of uric acid between the patients using diuretics $(N=11$, average uric acid level $335 \mu \mathrm{mol} / \mathrm{L})$ and those who did not use diuretics $(N=39$, uric acid level $343.8 \mu \mathrm{mol} / \mathrm{L})$ when enrolled in our study $(p=$ 0.5922), and there is no significant differences in BMI between patients with baseline hyperuricemia and normouricemia.

Despite our attempts to control the maximum number of variables, we consider that our report has several limitations. First, due to the small number of patients with CTD, we could not separate patients by gender. Second, because CTD-PAH is more common in young people, we could only include a small number of patients over 65 years. Thus, our study is not fully representative of the whole population. Third, because only a few patients with UA re-examination value were diagnosed by right cardiac catheterization, we included CTD-PH pateients for ultrasonographic diagnosis. Finally, we did not perform routine insulin measuements, given that only two patients included had diabetes mellitus. Moreover we identified normal levels of fasting blood glucose in all participants.

In summary, UA levels might reflect disease severity and patient prognosis. Therefore, we purpose UA levels can be used to evaluate the severity, treatment efficiency and prognosis of patients with clinically confirmed CTD-PAH.

\section{Supplementary information}

Supplementary information accompanies this paper at https://doi.org/10. 1186/s12890-020-01309-1.

\footnotetext{
Additional file 1: Supplementary Figure 1. A Kaplan-Meier survival curves of the four patient groups, according to UA level variation; $p=$ 0.022; B: Kaplan-Meier survival curves of patients with increasing uricemia during the follow up period (UA: $\mathrm{N} \rightarrow \mathrm{H}$ ) and patients with steady normouricemia (UA: N $\rightarrow N$ ), $p=0.83$; C Kaplan-Meier 5-year survival curves of patients with increasing uricemia during the follow-up period $(\mathrm{UA}: \mathrm{N} \rightarrow \mathrm{H})$ and patients with steady normouricemia $(\mathrm{UA}: \mathrm{N} \rightarrow \mathrm{N}), p=$ 0.26; D: Kaplan-Meier 5-8 year survival curves of patients with increasing uricemia during the follow-up period (UA: $\mathrm{N} \rightarrow \mathrm{H}$ ) and patients with steady uricemia $(\cup A: N \rightarrow N), p=0.025$
}

\footnotetext{
Abbreviations

UA: Uric acid; IPAH: Idiopathic pulmonary arterial hypertension; CTD$\mathrm{PAH}$ : Pulmonary arterial hypertension secondary to connective tissue disease; CTD-PH: Pulmonary hypertension secondary to connective tissue disease; ACR: American Rheumatism Association; HIV: Human immunodeficiency virus; PH: Pulmonary hypertension; PVR: Pulmonary vascular resistance; PAH: Pulmonary arterial hypertension; CTD: Connective tissue disease; SLE: Systemic lupus erythematosus; SSc-PAH: PAH secondary to systematic sclerosis; ECHO: Echocardiogram; RHC: Right cardiac catheterization; pSS: Primary Sjogren's syndrome; SSc: Systematic sclerosis; MCTD: Mixed connective tissue disease; mPAP: Mean pulmonary arterial pressure; PAWP: Pulmonary arterial wedge pressure; ILD: Interstitial lung disease;
} 
HRCT: High-resolution computed tomography; NT-proBNP: N-terminal pro-Btype natriuretic peptide; CO: Cardiac output; Cl: Cardiac index; $\mathrm{SVO}_{2}$ : Mixed venous oxygen saturation; WHO-FC: World Health Organization Cardiac Function Classification; PASP: Pulmonary artery systolic pressure; RAP: Right atrial pressure; ROS: Generates reactive oxygen species; NO: Nitric oxide; MAPK: Mitogen activated protein kinases; COX-2: Cyclooxygenase-2; PDGF: Platelet-derived growth factor

\section{Acknowledgements}

Thanks to the patients involved in this retrospective study.

\section{Authors' contributions}

JW was responsible for the concept and design of the study. JW analysed the data and MZ and WQ oversaw all analyses. MZ, WQ and JW were responsible for data interpretation and drafting the manuscript. $\mathrm{YW}, \mathrm{XL}, \mathrm{YH}$ $\mathrm{XS}, \mathrm{QW}$ revised the manuscript critically for intellectual content. All authors have approved the final version to be published and are jointly accountable for all aspects of the work

\section{Funding}

This study was supported by National Natural Science Foundation of China (NSFC) (81671615 and 81701610 and 81302575): Xuzhou science and technology plan in 2020 (KC20131); a project Funded by the Priority Academic Program Development of Jiangsu Higher Education Institutions (PAPD), Young Medical People Project in Jiangsu Province and Medical Tallent of Empowering Medicine through Science and Education Program.

\section{Availability of data and materials}

The datasets used and analysed during the current study are available from the corresponding author on reasonable request

\section{Ethics approval and consent to participate}

This study was approved by the Medical Ethics Committee of the First Affiliated Hospital of Nanjing Medical University (number 2018-SR-333). Written informed consent have been obtained from all participants.

\section{Consent for publication}

Not applicable.

\section{Competing interests}

The authors declare that they have no competing interests.

\section{Author details}

'Department of Rheumatology, The First Affiliated Hospital of Nanjing Medical University, Nanjing, China. ${ }^{2}$ Xuzhou Central Hospital, Xuzhou, China.

\section{Received: 26 February 2020 Accepted: 9 October 2020}

\section{Published online: 19 October 2020}

\section{References}

1. Li M, Wang Q, Zhao J, Li Z, Ye Z, Li C, Li X, Zhu P, Wang Z, Zheng Y, et al. Chinese SLE treatment and research group (CSTAR) registry: II. Prevalence and risk factors of pulmonary arterial hypertension in Chinese patients with systemic lupus erythematosus. Lupus. 2014;23(10):1085-91.

2. Aghdashi M, Behnemoon M, Mahmoodi RJ, Rabiepour M. Evaluation of serum uric acid level in systemic lupus erythematosus patients with normal and high pulmonary arterial hypertension. Biomedicine (Taipei). 2018;8(3):16.

3. Castillo-Martinez D, Marroquin-Fabian E, Lozada-Navarro AC, Mora-Ramirez M, Juarez M, Sanchez-Munoz F, Vargas-Barron J, Sandoval J, AmezcuaGuerra LM. Levels of uric acid may predict the future development of pulmonary hypertension in systemic lupus erythematosus: a seven-year follow-up study. Lupus. 2016;25(1):61-6.

4. Kim KJ, Baek IW, Park YJ, Yoon CH, Kim WU, Cho CS. High levels of uric acid in systemic lupus erythematosus is associated with pulmonary hypertension. Int J Rheum Dis. 2015:18(5):524-32.

5. Seyyedi SR, Menkmohammad M, Chitsazan M, Behzadnia N, Sadr M, Hashemian SM, Sharif-Kashani B. Relationship between Serum Uric Acid Levels and the Severity of Pulmonary Hypertension. Tanaffos. 2017;16(4):283-8.

6. Luo DL, Zhang CJ, Huang YG, Huang T, Li HZ. Serum uric acid is associated with disease severity and an important predictor for clinical outcome in patients with pulmonary hypertension. Zhonghua Xin Xue Guan Bing Za Zhi. 2017:45(6):496-500.

7. Zhang CY, Ma LL, Wang LX. Relationship between serum uric acid levels and ventricular function in patients with idiopathic pulmonary hypertension. Exp Clin Cardiol. 2013;18(1):e37-9.

8. Li ZN, He JG, Liu ZH, Gu Q, Ni XH, Cheng XS, Xiong CM. Relationship between serum uric acid levels and patient conditions and prognosis in idiopathic pulmonary arterial hypertension. Natl Med J China. 2012;92(46):3261-4.

9. Dimitroulas T, Giannakoulas G, Dimitroula H, Sfetsios T, Parcharidou D, Karvounis $H$, Settas L. Significance of serum uric acid in pulmonary hypertension due to systemic sclerosis: a pilot study. Rheumatol Int. 2011; 31(2):263-7.

10. Van Albada ME, Loot FG, Fokkema R, Roofthooft MT, Berger RM. Biological serum markers in the management of pediatric pulmonary arterial hypertension. Pediatr Res. 2008:63(3):321-7.

11. Jiang $X$, Han $Z Y$, Wang $Y, X u X Q, M a C R$, Wu $Y$, Pan $L$, Jing $Z C$. Hemodynamic variables and clinical features correlated with serum uric acid in patients with pulmonary arterial hypertension. Chin Med J. 2008;121(24): 2497-503.

12. Bendayan D, Shitrit D, Ygla M, Huerta M, Fink G, Kramer MR. Hyperuricemia as a prognostic factor in pulmonary arterial hypertension. Respir Med. 2003; 97(2):130-3.

13. Nagaya N, Uematsu M, Satoh T, Kyotani S, Sakamaki F, Nakanishi N, Yamagishi M, Kunieda T, Miyatake K. Serum uric acid levels correlate with the severity and the mortality of primary pulmonary hypertension. Am J Respir Crit Care Med. 1999;160(2):487-92.

14. Kula S, Canbeyli F, Atasayan V, Tunaoglu FS, Oguz AD. A retrospective study on children with pulmonary arterial hypertension: A single-center experience. Anatol J Cardiol. 2018;20(1):41-7.

15. Wang LY, Lee KT, Lin CP, Hsu LA, Wang CL, Hsu TS, Ho WJ. Long-Term Survival of Patients with Pulmonary Arterial Hypertension at a Single Center in Taiwan. Acta Cardiol Sin. 2017:33(5):498-509.

16. Ozpelit E, Akdeniz B, Sezgin D, Sevinc C, Tertemiz KC, Ozpelit ME, Baris M, Baris N. Clinical and hemodynamic profiles of elderly patients with pulmonary arterial hypertension: a single center, prospective study. J Geriatr Cardiol. 2017:14(1):20-7.

17. Dhaun N, Vachiery JL, Benza RL, Naeije R, Hwang LJ, Liu X, Teal S, Webb DJ. Endothelin antagonism and uric acid levels in pulmonary arterial hypertension: clinical associations. J Heart Lung Transplant. 2014;33(5):521-7.

18. Njaman W, lesaki T, Iwama Y, Takasaki Y, Daida H. Serum uric Acid as a prognostic predictor in pulmonary arterial hypertension with connective tissue disease. Int Heart J. 2007:48(4):523-32.

19. Wensel R, Opitz CF, Anker SD, Winkler J, Hoffken G, Kleber FX, Sharma R, Hummel M, Hetzer R, Ewert R. Assessment of survival in patients with primary pulmonary hypertension: importance of cardiopulmonary exercise testing. Circulation. 2002;106(3):319-24.

20. Huang C, Li M, Liu Y, Wang Q, Guo X, Zhao J, Lai J, Tian Z, Zhao Y, Zeng X. Baseline Characteristics and Risk Factors of Pulmonary Arterial Hypertension in Systemic Lupus Erythematosus Patients. Medicine (Baltimore). 2016;95(10): e2761.

21. Simpson CE, Damico RL, Hummers L, Khair RM, Kolb TM, Hassoun PM, Mathai SC. Serum uric acid as a marker of disease risk, severity, and survival in systemic sclerosis-related pulmonary arterial hypertension. Pulm Circ. 2019;9(3):2045894019859477.

22. Naing P, Kuppusamy H, Scalia G, Hillis GS, Playford D. Non-invasive assessment of pulmonary vascular resistance in pulmonary hypertension: current knowledge and future direction. Heart Lung Circ. 2017:26(4):323-30.

23. Yan C, Xu Z, Jin J, Lv J, Liu Q, Zhu Z, Pang K, Shi Y, Fang W, Wang Y. A feasible method for non-invasive measurement of pulmonary vascular resistance in pulmonary arterial hypertension: combined use of transthoracic Doppler-echocardiography and cardiac magnetic resonance. Non-invasive estimation of pulmonary vascular resistance. Int J Cardiol Heart Vasc. 2015;9:22-7

24. Zharikov S, Krotova K, Hu H, Baylis C, Johnson RJ, Block ER, Patel J. Uric acid decreases NO production and increases arginase activity in cultured pulmonary artery endothelial cells. Am J Physiol Cell Physiol. 2008;295(5): C1183-90.

25. Kang DH, Han L, Ouyang X, Kahn AM, Kanellis J, Li P, Feng L, Nakagawa T, Watanabe S, Hosoyamada M, et al. Uric acid causes vascular smooth muscle cell proliferation by entering cells via a functional urate transporter. Am J Nephrol. 2005;25(5):425-33. 
26. Watanabe S, Kang DH, Feng L, Nakagawa T, Kanellis J, Lan H, Mazzali M, Johnson RJ. Uric acid, hominoid evolution, and the pathogenesis of saltsensitivity. Hypertension. 2002;40(3):355-60.

27. Kang DH, Nakagawa T, Feng L, Watanabe S, Han L, Mazzali M, Truong L,

Harris R, Johnson RJ. A role for uric acid in the progression of renal disease. J Am Soc Nephrol. 2002;13(12):2888-97.

28. Corry DB, Eslami P, Yamamoto K, Nyby MD, Makino H, Tuck ML. Uric acid stimulates vascular smooth muscle cell proliferation and oxidative stress via the vascular renin-angiotensin system. J Hypertens. 2008;26(2):269-75.

29. Rao GN, Corson MA, Berk BC. Uric acid stimulates vascular smooth muscle cell proliferation by increasing platelet-derived growth factor A-chain expression. J Biol Chem. 1991;266(13):8604-8.

30. Volkov AV, ludkina NN, Nikolaeva EV, Kurmukov IA, Glukhova SI, Nasonov EL, Bosentan: a considerable increase in the survival of patients with pulmonary hypertension associated with systemic rheumatic diseases. Ter Arkh. 2014; 86(5):32-9.

31. Leberkuhne L, Ploegstra MJ, Douwes JM, Bartelds B, Roofthooft MT, Hillege HL, Berger RM. Serially Measured Uric Acid Levels Predict Disease Severity and Outcome in Pediatric Pulmonary Arterial Hypertension. Am J Respir Crit Care Med. 2017;195(3):401-4.

32. Zhao J, Wang Q, Liu Y, Tian Z, Guo X, Wang H, Lai J, Huang C, Yang X, Li M, et al. Clinical characteristics and survival of pulmonary arterial hypertension associated with three major connective tissue diseases: a cohort study in China. Int J Cardiol. 2017:236:432-7.

\section{Publisher's Note}

Springer Nature remains neutral with regard to jurisdictional claims in published maps and institutional affiliations.

Ready to submit your research? Choose BMC and benefit from:

- fast, convenient online submission

- thorough peer review by experienced researchers in your field

- rapid publication on acceptance

- support for research data, including large and complex data types

- gold Open Access which fosters wider collaboration and increased citations

- maximum visibility for your research: over $100 \mathrm{M}$ website views per year

At $\mathrm{BMC}$, research is always in progress.

Learn more biomedcentral.com/submissions 